\title{
Analysis and Optimisation of Disc Brake System for Two-Wheeler Applications
}

\author{
Jaison Mathew Zacharia, Hari Krishna Shaji, Jerald James, Sree Ram H.
}

\begin{abstract}
Braking system is used for restraining the motion by absorbing energy from a moving body. The conventional braking system works on the principle of friction. Among the different types of brakes, disc brake is one of the most widely used braking systems. Estimation of efficiency of this class of brakes without manufacturing of prototype is very difficult. This paper focusses on analysis and optimization of disc brake using ANSYS software. The base modelling of the disc brake system will be carried out using SOLIDWORKS and the model will be imported to ANSYS. The analysis is aiming at optimizing the deformation and stress conditions. The final design is aiming at controlling the deformation and stresses of the disc by providing the best material to be used for the certain design. The basic brake system used for the analysis was Bajaj Pulsar 150 motor cycles.
\end{abstract}

Key words: Disc Brake, ANSYS, Modeling, Caliper, Friction.

\section{INTRODUCTION}

$\mathrm{T}$ he disc brake is used for controlling the speed of the vehicle using the friction caused by forcing the brake pads against a disc with a pair of calipers. The brake disc is generally made of cast iron or composites such as reinforced carbon or ceramic matrix composites. For the control of vehicle, friction material in the form of brake pads is attached to the caliper. The calipers are movedmechanically, hydraulically, pneumatically or electromagnetically against both sides of the disc. The friction causes the rotating disc and the wheel to slow or stop.

Disc-style brakes were developed and used first in England in the 1890s. Frederick William Lanchester introduced the first disc brake and was successfully used on his Lanchester cars. Compared to drum brakes, disc brakes offer better braking efficiency, due to better cooling. A disc brake consists of a cast iron disc screwed to the wheel hub and a stationary housing called caliper. The caliper is connected to a stationary part of the vehicle like the axle casing or the stub axle. In between the pistons and the disc there is a friction pad held in position by the retaining pins, spring plates etc. Each cylinder has a sealing ring between the cylinder and piston.

Disc brakes are one of the major safety concerns due to its functionality in a vehicle. When the driver presses on the

Revised Manuscript Received on December 15, 2019

* Correspondence Author

Sreeram H, Faculty of Amal Jyothi College of Engineering, Kanjirapally-686518, India E-mail: hsreeram@amaljyothi.ac.in

Jaison Mathew Zacharia*, Research Scholar, Department of Automobile Engineering, Amal Jyothi College of Engineering, Kanjirapally-686518, India. Email: jaison.pannackal@ gmail.com

Hari Krishna Shaji*, Research Scholar, Department of Automobile Engineering, Amal Jyothi College of Engineering, Kanjirapally-686518, India. E-mail:hk912452@gmail.com

Jerald James*, Research Scholar, Department of Automobile Engineering, Amal Jyothi College of Engineering, Kanjirapally-686518,India.E-mail:jeraldjamesthonakkara@gmail.com brake pedal, hydraulic fluid is forced on the piston of the caliper, which in turn forces the brake pads into the rotating rotor. The frictional forces at the meeting faces between the pads and the rotor reduces the rotational movement of the rotor and the axle on which it is mounted and fitted. The kinetic energy of the vehicle is converted into heat that is dissipated to the atmosphere through pads and discs.

\section{MATHEMATICAL MODELLING}

A model replicates the system which serves the defined purpose. This work aims at developing a finite element (FE) model for the structural analysis of the disc brake used in the front wheel of a Bajaj Pulsar 150. The structural analysis aims at computing the pad-to-rotor shear stress distribution. The disc brake assembly consists of a ventilated rotor, a floating caliper, and a pair of brake pads. The brake pad mounted on the piston side is known as the piston-side brake pad, and the pad on the opposite side is named as the finger-side brake pad. The connection between the brake and the suspension system is through a knuckle, to the drive through a wheel bearing and the caliper is connected to the hydraulic brake line. The components meet at geometrical boundaries, referred to as mating faces.

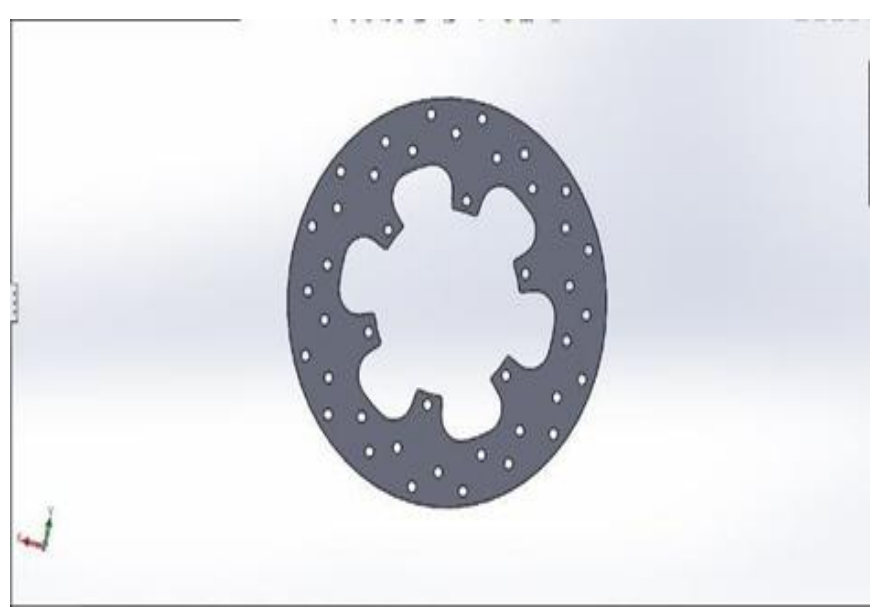

Fig1: 3D drawing of Disc Brake carried out in SolidWorks

The model needs to be created considering the interactions between the mating components. The model should always be as simple but should serve the purpose of analysis. It is recommended to create a modular model architecture dividing the whole system model into a component model. 


\section{Analysis and Optimisation of Disc Brake System for Two-Wheeler Applications}

\section{ANA.LYSIS}

The finite element analysis software ANSYS 17.0 is used for carrying out the analysis using the $3 \mathrm{D}$ model created in Solidworks. The FE model pursues the same structure as the geometric model. In the FE model a mating feature consists of nodes representing the mating face in the geometrical model.

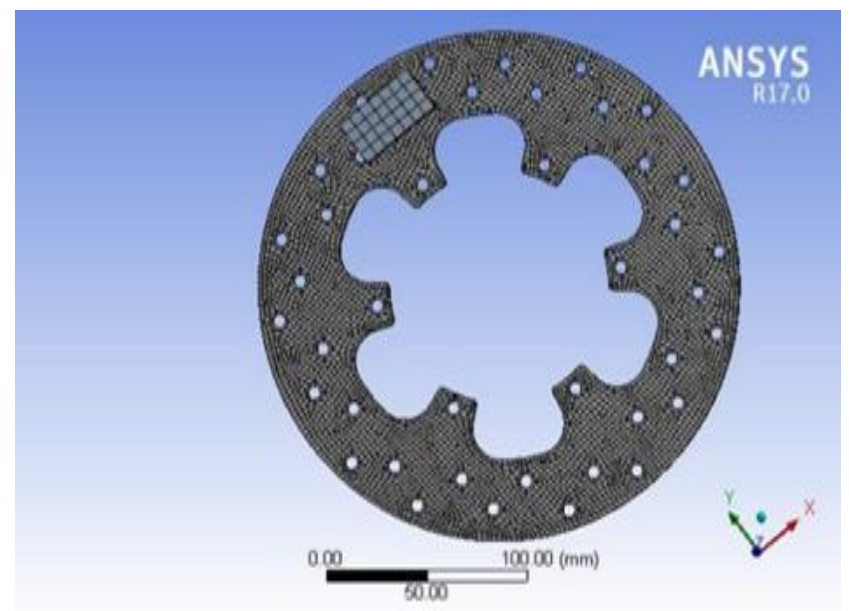

Fig 2: FE model meshed to a size of $2.5 \mathrm{~mm}$

In ANSYS, general contact between two bodies is superimposed in a model by creating a set of contact elements overlaying the elements describing the boundary of the first body, and a set of target elements overlaying the boundary elements describing the second body. Contact occurs when the contact element touches the target elements. The contact and target elements assume the same shape as the underlying element face.

The deformable bodies of the subsystem are meshed with a characteristic mesh size of $2.5 \mathrm{~mm}$ and the software analysis is carried out.

\section{RESULT AND DISCUSSION}

The Table 1, 2 and 3 provides the details of the values obtained for the deformation, equivalent stress and shear stress in the analysis carried out using Ansys for different materials using dynamic analysis. The graphs were plotted with these values which are provided in Figures 3, 4 and 5.

- Total Deformation

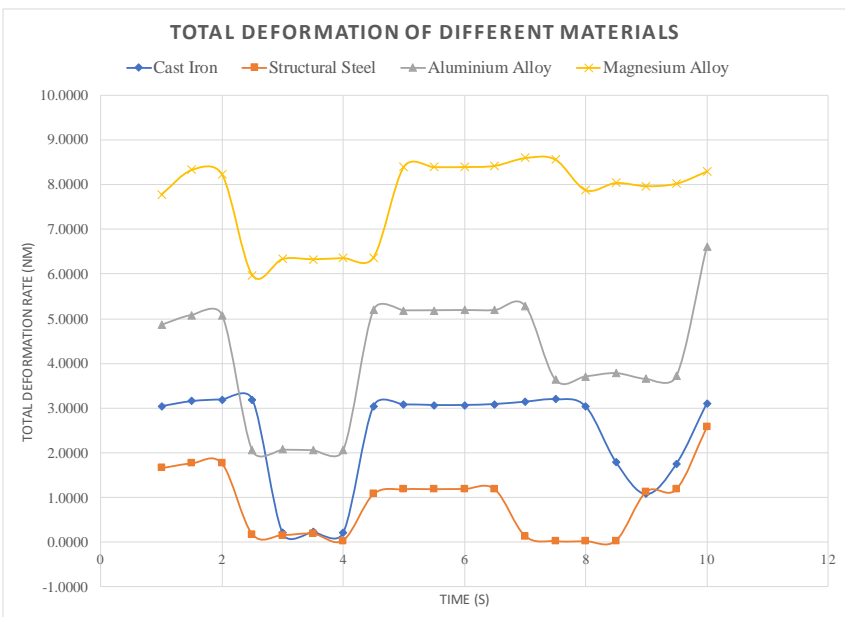

Fig 3: Total Deformation of different materials
Table-1: Total Deformation chart

\begin{tabular}{|c|c|r|r|c|}
\hline \multicolumn{5}{|c|}{ Total Deformation (nm) } \\
\hline $\begin{array}{c}\text { Tim } \\
\text { e (s) }\end{array}$ & Cast & $\begin{array}{c}\text { Structur } \\
\text { al Steel }\end{array}$ & $\begin{array}{c}\text { AluminumAl } \\
\text { loy }\end{array}$ & $\begin{array}{c}\text { MagnesiumA } \\
\text { lloy }\end{array}$ \\
\hline 1 & 3.0425 & 1.661 & 4.864 & 7.7809 \\
\hline 1.5 & 3.1544 & 1.769 & 5.0815 & 8.3309 \\
\hline 2 & 3.1916 & 1.764 & 5.0804 & 8.2316 \\
\hline 2.5 & 3.1928 & 0.17243 & 2.0547 & 5.9756 \\
\hline 3 & 0.2081 & 0.15672 & 2.0755 & 6.3348 \\
\hline 3.5 & 0.2342 & 0.18832 & 2.0644 & 6.3292 \\
\hline 4 & 0.2210 & 0.037527 & 2.0648 & 6.3557 \\
\hline 4.5 & 3.0451 & 1.077 & 5.1948 & 6.3715 \\
\hline 5 & 3.0804 & 1.185 & 5.1851 & 8.3973 \\
\hline 5.5 & 3.0669 & 1.189 & 5.187 & 8.3951 \\
\hline 6 & 3.0683 & 1.193 & 5.1916 & 8.3966 \\
\hline 6.5 & 3.089 & 1.189 & 5.1917 & 8.4238 \\
\hline 7 & 3.1412 & 0.13628 & 5.2889 & 8.5956 \\
\hline 7.5 & 3.1952 & 0.019323 & 3.6404 & 8.5644 \\
\hline 8 & 3.0369 & 0.018678 & 3.7106 & 7.8799 \\
\hline 8.5 & 1.7961 & 0.030173 & 3.7838 & 8.0387 \\
\hline 9 & 1.079 & 1.131 & 3.6536 & 7.968 \\
\hline 9.5 & 1.7598 & 1.191 & 3.7231 & 8.0242 \\
\hline 10 & 3.1067 & 2.581 & 6.6149 & 8.2952 \\
\hline
\end{tabular}

In this graph, the blue line represents cast iron, orange line represents the structural steel, the grey line represents the aluminum alloy and the yellow line represents the magnesium alloy. It was observed that the total deformation is minimum for structural steel and the maximum for magnesium alloy.

- Equivalent Stress

$$
\begin{aligned}
& \text { EQUIVALENT STRESS OF DIFFERENT MATERIALS } \\
& \rightarrow \text {-Cast Iron } \quad-\rightarrow \text {-Structural Steel } \quad \text {-Aluminium Alloy } \quad * \text { Magnesium Alloy }
\end{aligned}
$$

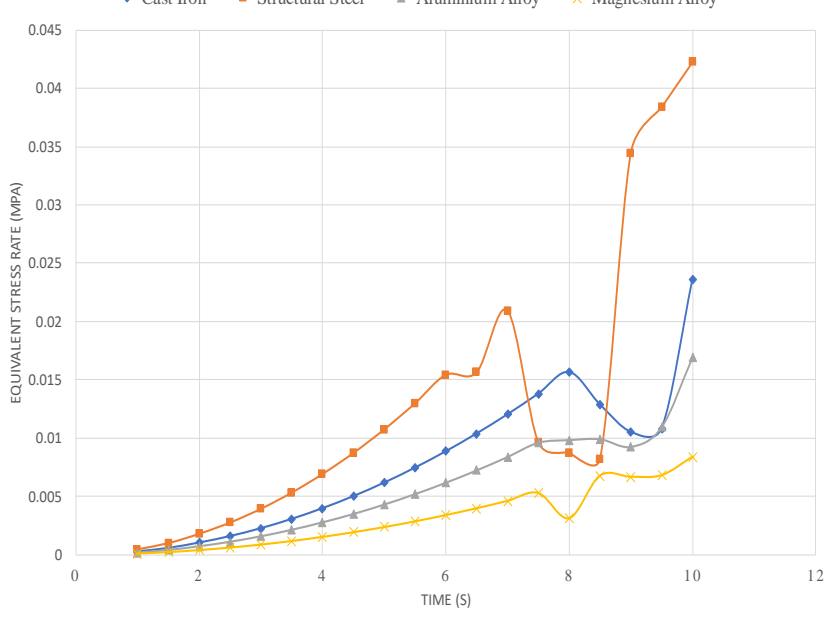

Fig 4: Equivalent Stress of different materials 
International Journal of Innovative Technology and Exploring Engineering (IJITEE) ISSN: 2278-3075, Volume-9 Issue-2S2, December 2019

Table 2: Equivalent Stress chart

\begin{tabular}{|c|c|c|c|c|}
\hline \multicolumn{5}{|c|}{ Equivalent Stress (MPa) } \\
\hline $\begin{array}{c}\text { Time } \\
\text { (s) }\end{array}$ & $\begin{array}{c}\text { Cast } \\
\text { Iron }\end{array}$ & $\begin{array}{c}\text { Structural } \\
\text { Steel }\end{array}$ & $\begin{array}{c}\text { Aluminum } \\
\text { Alloy }\end{array}$ & $\begin{array}{c}\text { Magnesium } \\
\text { Alloy }\end{array}$ \\
\hline 1 & 0.00024 & 0.000418 & 0.0001672 & 0.0000919 \\
\hline 1.5 & 0.000543 & 0.000945 & 0.0003781 & 0.0002078 \\
\hline 3.5 & 0.003036 & 0.0052844 & 0.0021141 & 0.0011619 \\
\hline 2 & 0.001004 & 0.001748 & 0.0006993 & 0.0003844 \\
\hline & 0.002237 & 0.0038937 & 0.0015577 & 0.0008562 \\
\hline & 0.001559 & 0.0027149 & 0.0010861 & 0.000597 \\
\hline & & & & \\
\hline
\end{tabular}

\begin{tabular}{|c|c|c|c|c|}
\hline 4 & 0.003956 & 0.0068869 & 0.0027551 & 0.0015143 \\
\hline 4.5 & 0.004991 & 0.0086885 & 0.0034741 & 0.0019132 \\
\hline 5 & 0.006152 & 0.010715 & 0.0042853 & 0.0023536 \\
\hline 5.5 & 0.007439 & 0.012953 & 0.0051805 & 0.0028456 \\
\hline 6 & 0.008846 & 0.015402 & 0.0061602 & 0.0033841 \\
\hline 7.5 & 0.013793 & 0.0096045 & 0.0096009 & 0.005279 \\
\hline 7 & 0.012022 & 0.020905 & 0.0083741 & 0.0046005 \\
\hline & & & & \\
\hline
\end{tabular}

\begin{tabular}{|c|c|c|c|c|}
8.5 & 0.012859 & 0.0081621 & 0.0099038 & 0.006765 \\
\hline 9 & 0.010512 & 0.034438 & 0.0092416 & 0.0066694 \\
\hline 9.5 & 0.010816 & 0.038366 & 0.010924 & 0.0068056 \\
\hline 10 & 0.023626 & 0.042224 & 0.016907 & 0.0083815 \\
\hline
\end{tabular}

From the graph and the table, the equivalent stress was observed to be minimum for magnesium alloy and maximum for structural steel.

- Shear Stress

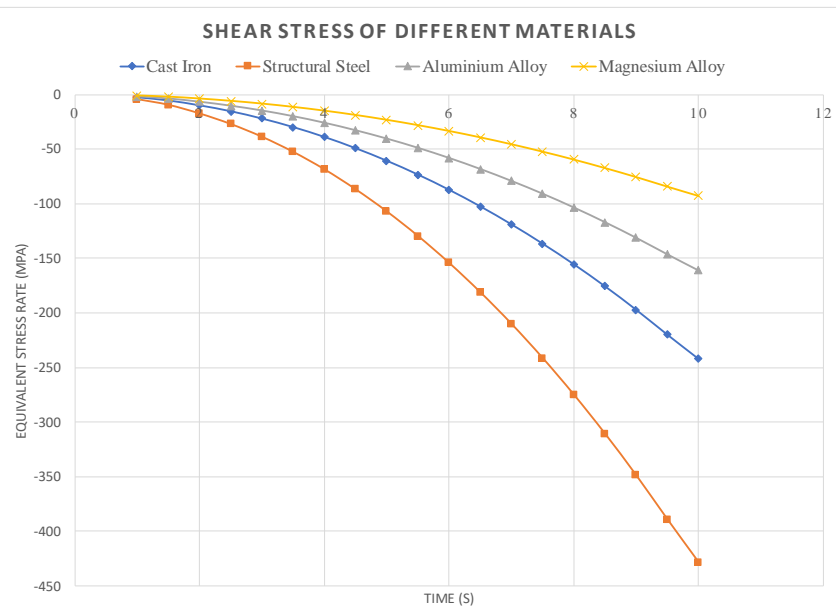

Fig 5: Shear Stress of different materials

Table 3: Shear Stress Chart

\begin{tabular}{|c|c|c|c|c|}
\hline \multicolumn{5}{|c|}{ Shear Stress (MPa) } \\
\hline $\begin{array}{c}\text { Time } \\
(\mathbf{s})\end{array}$ & $\begin{array}{l}\text { Cast } \\
\text { Iron }\end{array}$ & $\begin{array}{c}\text { Structural } \\
\text { Steel }\end{array}$ & $\begin{array}{l}\text { Aluminum } \\
\text { Alloy }\end{array}$ & $\begin{array}{c}\text { Magnesium } \\
\text { Alloy }\end{array}$ \\
\hline 1 & -2.4603 & -4.2756 & -1.6766 & -1.0085 \\
\hline 1.5 & -5.3959 & -9.4734 & -3.6319 & -2.1244 \\
\hline 2 & -9.8711 & -17.399 & -6.6068 & -3.8373 \\
\hline 2.5 & -15.27 & -27.077 & -10.25 & -5.9313 \\
\hline 3 & -21.964 & -38.76 & -14.64 & -8.4518 \\
\hline 3.5 & -29.762 & -52.575 & -19.834 & -11.435 \\
\hline 4 & -38.778 & -68.534 & -25.835 & -14.883 \\
\hline 4.5 & -49.083 & -86.815 & -32.719 & -18.796 \\
\hline 5 & -60.562 & -107.11 & -40.346 & -23.222 \\
\hline 5.5 & -73.249 & -129.59 & -48.797 & -28.076 \\
\hline 6 & -87.185 & -154.26 & -58.074 & -33.405 \\
\hline 6.5 & -102.37 & -181.14 & -68.181 & -39.219 \\
\hline 7 & -118.84 & -210.14 & -79.119 & -45.495 \\
\hline 7.5 & -136.53 & -241.44 & -90.825 & -52.25 \\
\hline 8 & -155.39 & -274.99 & -103.44 & -59.46 \\
\hline 8.5 & -175.58 & -310.8 & -116.91 & -67.193 \\
\hline 9 & -197.09 & -348.9 & -131.22 & -75.411 \\
\hline 9.5 & -219.88 & -389.23 & -146.38 & -84.122 \\
\hline 10 & -242.06 & -428.49 & -161.12 & -92.598 \\
\hline
\end{tabular}

When comparing all the values of the different materials, it was found out that Magnesium Alloy is the best material according to the design. 


\section{COST ANALYSIS}

Cost is a one of the major criteria for the selection of materials for a component. The rates of the different materials under consideration are:

Table 4: Price Rates

\begin{tabular}{|c|c|}
\hline Materials & Rupees/kg* (*as on 07/19) \\
\hline Cast Iron & 50 \\
\hline Structural Steel & 40 \\
\hline Aluminum Alloy & 120 \\
\hline Magnesium Alloy & 110 \\
\hline
\end{tabular}

It is observed that the magnesium alloys were more than double the price when compared to cast iron. But when we compare the performance and which will have direct impact on life, it is recommended to have magnesium alloys considering the long-term benefits that can be observed by the usage.

\section{CONCLUSION}

In this work, the comparative study of different materials which are used for brake disc in a disc brake were carried out. Based on the deformation and the stresses induced, it was found that magnesium alloy provides the better performance characteristics when compared to other materials under consideration.

\section{FUTURE SCOPE}

The thermal analysis of heat dissipation and absorption was not carried out in the present paper which can provide more insight in the area of material selection of brake discs. The study can also be conducted by using different composite materials and comparing the materials and identifying the better material for the specified usage.

\section{REFERENCES}

1. Thilak, V. M. M., Krishnaraj, R., Sakthivel, M.,

Kanthavel, K., G, D. M. M., \& Palani, R.(2011). researchpape

-Thermal-and-Structural-Analysis-of-the-Rotor-Disc-of -Disc-Brake.pdf, 2(8), 2-5.

2. Stimson, I. L., \& Fisher, R. (1980). Design and engineering of carbon brakes. Phil. Trans. i?. Soc. Lond. A, 294, 583-590.

3. Mackin, T. J., Noe, S. C., Ball, K. J., Bedell, B. C., Bim-Merle, D. P., Bingaman, M. C., ...

Zimmerman, R. S. (2002). Thermal cracking in disc brakes.Engineering Failure Analysis, 9(1), 63-76.

4. Lee, K., \& Dinwiddie, R. B. (1998). Conditions of frictional contact in disk brakes and their effects on Brake Judder. SAE Technical Papers.

5. Jacobsson, H. (2003). Aspects of disc brake judder. Proceedings of the Institution ofMechanicalEngineers,
Part D: Journal of Automobile Engineering, 217(6), 419-430.

6. Hegadekatte, V., Huber, N., \& Kraft, O. (2005). Finite element based simulation of dry sliding wear. Modelling and Simulation in Materials Science and Engineering, 13(1), 57-75.

7. Eriksson, M., \& Jacobson, S. (2001). Friction behaviour and squeal generation of disc brakes at low speeds. Proceedings of the Institution of Mechanical Engineers, Part D: Journal of Automobile Engineering, 215(12), 1245-1256.

8. Me, L. De. (2015). Two- / three-dimensional hybrid model of the thermomechanical behaviour of disc brakes, 218, 17-30.

9. Day, A. J., Tirovic, M., \& Newcomb, T. P. (1991). Thermal effects and pressure distributions in brakes. Proceedings of the Institution of Mechanical Engineers, Part D: Journal of Automobile Engineering, 205(3), 199-206.

10. Day, A. J., \& Newcomb, T. P. (1984). The Dissipation of Frictional Energy from the Interface of an Annular Disc Brake. Proceedings of the Institution of Mechanical Engineers, PartJournal of Automobile Engineering, 19.

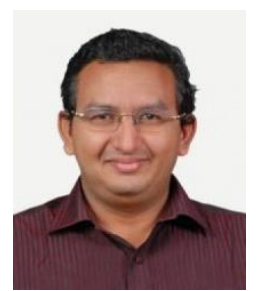

\section{AUTHORS PROFILE}

SreeramHcompleted his Masters degreein Technology from VIT University Vellore in 2012 and Bachelors degree in Technology from University of Kerala in 1999. He is having nearly nine years of industrial experience in the area of vehicle design, prototype development, vendor development, homologation, productivity improvement and production planning. $\mathrm{He}$ is pursuing in $\mathrm{PhD}$ in Kalasalingam University in the area of "Finite element methods in Electric Discharge Machining". He is presently working as an Assistant Professor in the Department of Mechanical Engineering (Automobile) in Amal Jyothi College. He is member of the curriculum committee for syllabus revision of APJ Abdul Kalam Technological University. He has also published a Data Book for "Engine and Vehicle Design" which is approved by the APJ Abdul Kalam Technological University for their examinations. He has presently 4 international conference papers published under his name.

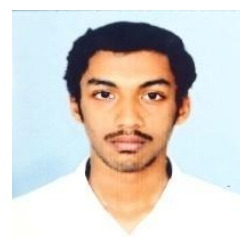

Jaison Mathew Zacharia completed his Bachelors degree in Automobile Engineering from APJ Abdul Kalam Technological University from Amal Jyoth College of Engineering, Kanjirapally in 2019. He has done his project on "Software analysis and optimization of disc brake". He is now currently working for another paper "Laser Ignition in gasoline engines" under the guidance of Sree Ram $\mathrm{H}$. He has attended many internships on automotive systemsand maintenance from giant companies like Bosch, Royal Enfield, Eicher and also Maruti Suzuki. He has studied and worked on many software's like CATIA, SOLIDWORKS, ANSYS, AUTOCAD for his project and other related works. He is a keen member of the "Society of Automotive Engineers" and has participated for the SAE BAJA INDIA. He has been certificated the Academy of CAD also certification on CATIA and also the certification for Ansys. 


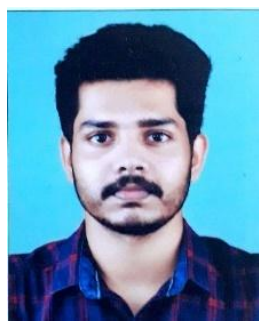

Hari Krishna Shajicompleted his Bachelors degree in Automobile Engineering from APJ Abdul Kalam Technological University from Amal Jyothi College of Engineering, Kanjirapally in 2019. An Active member of the Automobile Association.Has got the certification of CATIA.Participated in the technical talkshow on BMW future concepts. Has attended an internationalcourse on "Electric Vehicles-Design, Modelling and Simulation" conducted by Electrical Dept., College of Technology, Pantnagar, Uttarakhand.

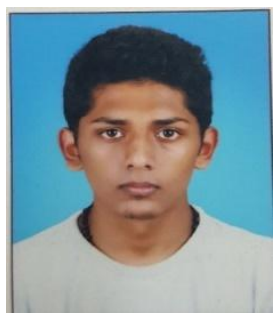

Jerald James completed his Bachelors degree in Automobile Engineering from APJ Abdul Kalam Technological University from Amal Jyothi College of Engineering, Kanjirapally in 2019. He is a University rank holder for Automobile Engineering for the batch 2015-2019. Has done bachelor thesis in "smart passenger ingress system in heavy transit vehicles. Conducted an industrial problem analysis at KondodyAutoKraft and also has done a funded project "Intelligent Transport rule management system (INTRIM). Active member of SAE. Attended GIAN course conducted by ministry of human resources on "Electric and Hybrid vehicle Technology". Attended several internships on automotive system architecture and maintenance from Giants like Bosch, Royal Enfield and Eicher. 